\title{
Current trends in the formation of international transport systems
}

\author{
Vera Baginova ${ }^{1}$, Andrey Zenkin ${ }^{1, *}$, and Dmitriy Ushakov ${ }^{1}$ \\ ${ }^{1}$ Russian University of Transport, Obraztsova str. 9, building 9, 127994, Moscow, Russia
}

\begin{abstract}
The purpose of the study is to establish and formalize current trends in the construction and formation of international transport systems. In this regard, first of all, the definition of international transport systems is given. In modern conditions, the formation and development of national transport systems is largely determined by the focus on international transport and economic relations, and the possibility of attracting international transit cargo flows to the transport system of countries. In this paper, all systems of existing transport corridors, Euro-Asian transport directions, transport of regions of economic cooperation and existing agreements on international routes and lines on different types of transport are considered in the axiomatic of their classification as international transport systems. A retrospective analysis of the development of international transport systems, their transformation and conversion in the process of evolution is given. In conclusion, the paper provides recommendations on the need for further research related to the theoretical and conceptual justification of trends in the formation of international transport systems, the study of legal support for their functioning, modeling the interaction of different types of transport, the prospects for their development, the possible assessment of efficiency and other issues related to this problem.
\end{abstract}

\section{Introduction}

The purpose of this study is to establish and formalize current trends in the construction and formation of international transport systems. At the same time, international transport systems are understood as integrated national transport systems or parts of these systems intended for carrying out passenger and cargo transportation in international traffic on the directions of their greatest concentration, formed on the basis of decisions taken by international organizations based on the results of conferences, meetings, work of interstate councils, including on transport, and fixed in the form of relevant declarations, agreements, reports and other normative documents.

Later in the work, all systems of existing transport corridors, Euro-Asian transport routes, transport regions of economic cooperation and existing agreements on international routes and lines on different types of transport (transport infrastructure) will be considered in the axiomatic of their classification as international transport systems.

\footnotetext{
* Coresponding author: zenkin1959@inbox.ru
} 
In modern conditions, the formation and development of national transport systems is largely determined by the focus on international transport and economic relations, and the possibility of attracting international transit cargo flows to the transport system of states [2].

Transport policy was declared one of the important areas of cooperation at the stage of formation of the European Community in the Treaty of Rome in 1957. However, within the framework of the interaction of the EEC states, the solution of transport problems did not have practical implementation until the mid -80's years [4].

The idea of creating transport corridors from North to South and from West to East of Europe was announced in the mid-80's years of the XX century. During the same period, the Inland transport Committee of the United Nations Economic Commission for Europe conducted studies and prepared relevant reports on the analysis of transport flows in NorthEastern Europe, the analysis of transport flows with the aim of applying an intermodal approach between France and the Iberian peninsula - the Maghreb countries, as well as Scandinavia and Southern Europe. Thus, methods have been developed to determine the appropriate use of individual modes of transport and their possible combination to select the main areas of transport provision and improvement of transport infrastructure. Later, the European Union began to play a leading role in both theoretical and practical development of the problem of international transport corridors.

The transport system is determined by the availability of the appropriate infrastructure, the necessary conditions for the promotion of vehicles and the management component.

In the Maastricht Treaty of 1992, a separate section on the creation of Trans-European networks was included in the transport section (Section XII "Trans-European networks", articles 129 "b" - 129 "d"). The four main objectives of the EU transport policy are formulated as follows: changing the balance between different modes of transport; removing "bottlenecks" in the transport infrastructure; focusing transport policy on specific users; getting the effect of transport globalization. In short, the requirements for the EU transport policy can be formulated as follows: efficiency, safety, and environmental protection.

The development of Trans-European transport networks (TEN-T) is intended to eliminate "bottlenecks" in a single Europe and contribute to solving not only transport problems directly, but also to serve social and environmental goals and the overall economic development of the European territory. Commission formulated the main principles for implementing TEN-T: concentration of funding on interstate projects, optimal allocation of Community resources, increased attention to the possibility of interaction of transport networks, consistent implementation of works and cooperation between countries.

In principle, such works were carried out in Europe until the early 90's and later. This is a set of Agreements developed and adopted by the Inland transport Committee of the United Nations Economic Commission for Europe: (AGR-1975, AGC-1985, AGTC-1991, AGN-1996) in the field of transport infrastructure. These Agreements serve as a legal basis for public authorities and governments of European countries to agree on plans for the creation and development of interconnected international networks of various types of inland transport in Europe in order to facilitate and develop international road, rail, combined transport, as well as inland waterway transport throughout the continent.

One of the priorities of the EU's transport policy has been and is the development of Trans-European networks mainly through the possibility of extending them beyond the EU borders, mainly in the Eastern direction, and, in cooperation with other countries, the creation of global transport corridors. 


\section{Materials}

In this regard, the development of a transport corridor development program has been initiated within the framework of the EU Commission, ECMT and UNECE. At the preparatory stage for the 1st Pan-European conference, relevant studies were conducted, which initially suggested the creation of 13 transport corridors. Subsequently, their number changed [4].

At the end of the twentieth century, serious geopolitical changes took place in Europe: the termination of the Council of Economic Mutual Assistance, which coordinates relations between the countries of the socialist camp, the collapse of the Soviet Union, and other changes that have consequences for the formation of interstate relations. To a large extent, these consequences have affected the operation of the transport sector and the functioning of transport systems [1].

In 1991, Prague hosted the first Pan-European transport conference, which was founded by the European Commission, the European conference of Ministers of transport (ECMT) and the UNECE. The conference adopted a Declaration on the pan-European transport policy, which, in particular, stated that "an Effective pan-European transport system (author's note.In essence, the international transport system) should be developed in accordance with the principles of a market economy and fair competition through the concept of a unified European transport system that meets the goals of social, environmental and energy policies, as well as safety requirements, and that is free from unreasonable restrictions, such as certain conditions for the load regime or certain technical or administrative barriers".

The second Pan-European transport conference, held in 1994 on the island of Crete, Greece, adopted a "Progress Report on the preparation of indicative guidelines for the further development of the pan-European transport infrastructure", based mainly on the Prague Declaration.

On the basis of the submitted documents, nine pan-European transport corridors (multimodal) were formed, which are of interest to the entire European continent, from the point of view of the development of transport infrastructure in Central and Eastern Europe. These transport directions are called "Crete corridors" and the concept of consideration in the development plan included three main levels: interrelated conduct long, medium and short-term activities of development of road and railway infrastructure.

The nine Crete corridors included eight road and rail corridors and one inland waterway route - the Danube river (other inland waterways, airports and ports were not included in the corridor concept). At the same time, it was determined that the main measures for infrastructure development should be aimed at increasing the capacity parameters of the infrastructure, in connection with the expected growth in traffic volumes and increasing traffic speeds, primarily on railway transport.

The main principle of development of transport infrastructure projects was the choice of options for their implementation based on the criterion of economic feasibility. At the same time, it was envisaged that the construction and formation of new transport routes should be considered only in the most exceptional cases. In addition, it was noted that the main focus should be on optimizing and implementing activities related to cross-border operations and services, since the time gain in increasing the speed of transport on the network sections will not be required if long delays of vehicles when crossing state borders are maintained.

Work on the Crete corridors continued for more than three years (until the third PanEuropean conference). During this time, significant progress has been made: participants have prepared and signed Memorandums of understanding for the development of each of the nine Crete corridors, and appropriate Organizational committees and technical secretariats have been established for each of them. Structurally, each of the Memorandum 
reflected the basic rules of research, the conditions for information exchange, the main technical standards, the algorithm for cooperation at border crossings and customs, as well as the possibility of using public-private partnerships (PPP), along with the use of national budgets. Thus, the Memorandums essentially reflected the issues of transport activities related to infrastructure, vehicles, and management impact.

Precisely after 1994 year, many researchers present different formulations of the ITC with various expanding comments, in principle, not affecting the very essence of the basic definition contained in the documents of European transport organizations.

The third pan-European transport conference was held in June 1997 in Helsinki. Based on a detailed and balanced analysis, the work performed by the interested parties, confirmed by the competent authorities of the UNECE and approved by the European Conference of Ministers of Transport (ECMT) has reached the following final results, as defined in the final documents of the conference.

The nine pan-European transport corridors in the Central and Eastern European region and the basic principles approved for the development of the Trans-European transport network (TEN-T) provide a full-fledged basis for coordinated infrastructure development at the pan-European level. The nine corridors that have already been adopted do not require significant changes or adjustments, except in cases where a new route must be provided or the missing connecting links connecting these transport corridors must be taken into account in a minimal amount. The conference approved the extension of the corridor II from Moscow to Nizhny Novgorod with the prospect of connection with the Trans-Siberian railway, which is the most important direction of the emerging Euro-Asian relations.

Taking into account the cessation of hostilities on the Balkan peninsula and the establishment of peaceful development processes in the countries that were formed on the site of the Socialist Federal Republic of Yugoslavia, the conference decided to create a new transport corridor (Corridor X), the direction of which corresponds in general to the traditional transport route that passes through South-Eastern Europe and was widely used before the outbreak of hostilities.

In addition, it became clear that the concept of transport corridors needs further development, due to the need to take into account transport links between the main centers of activity, which are not given due attention when determining the need for transport infrastructure in certain areas, and especially those that are adjacent to the sea or connected to sea basins. The adoption of additional refinements to the conceptual approach previously applied to corridors has allowed the adoption of the additional concept of pan-European transport Areas (PETrA). In this regard, it was suggested that interested countries and relevant regional cooperation organizations develop plans for the development of transport infrastructure in each such area based on the conclusion of appropriate Memorandums of understanding similar to those adopted for the corridors, taking into account their links with the pan-European corridors, the TEN-T transport system of the European Union, and, if possible, based on the existing expediency, provide for their connection with the Central Asian states. Thus, it was essentially a question of deeper integration of pan-European transport corridors with the transport of areas of general economic cooperation [6].

The following pan-European transport Areas (PETrA) were identified as priority Areas at the Conference):

Euro-Arctic region of the Barents sea (BEAR);

The area of the Black sea (BSEC);

Mediterranean basin area;

Area of the Adriatic and Ionian seas.

With regard to the Baltic sea region, which is essentially a natural candidate for becoming a pan-European transport Area, it was noted that there is currently a sufficient concentration of transport infrastructure of international importance in this region due to the 
passage of the corresponding sections of the corresponding pan-European corridors, there is also a positive trend towards resolving transport issues in this region through active participation in these processes and obtaining already certain positive results from the Council of the Baltic sea States and the corresponding Conference of transport ministers.

In the context of this study, each of the pan-European transport Areas (PETrA) can be considered as independent international transport systems in the context of their formation, development and future prospects in the light of ongoing integration processes.

Regarding the Black sea pan-European transport zone, it was noted that it is a coastal route connecting the coastal countries of the Black sea with the countries of Central and Eastern Europe - through the pan - European transport corridors, and then with access to the countries of the Caucasian isthmus and directions oriented to Central Asia through the transport corridor: Europe - Caucasus-Asia (TRACECA) and the Mediterranean panEuropean transport zone. In the context of consideration of the BSEC region, special attention was paid primarily to the TRACECA corridor, where a separate program of international cooperation was developed between the European Union and partner countries for the organization of the transport corridor, and an appropriate intergovernmental Commission was established in organizational terms.

The official recognition of the Euro-Arctic region of the Barents sea as a territorial structure of international cooperation occurred in 1993 with the creation of the Barents Euro-Arctic region Council (BEAC), a body of intergovernmental interaction between Russia, Denmark, Iceland, Norway, Finland, Sweden, and the Commission of the European communities. Nine countries - the United Kingdom of Great Britain and Ireland, France, Germany, the Netherlands, Poland, the United States, Canada, Japan, and Italy-were granted observer status in the BEAC. [5]

The Barents Euro-Arctic region includes territories located North of the Arctic circle or crossed by it. It includes the provinces of Nurland, Troms, Finnmark (Norway), Norrboten, Vesterbotten (Sweden), the development unions of the communes of Lapland, Kainuu, and Northern Ostrobothnia (Finland), and the regions of Russia: Murmansk region, Arkhangelsk region, Nenets Autonomous district, Republic of Karelia, and Komi Republic.

In order to expand cross-border cooperation in the Barents region, the Ministers of transport of Finland, Norway, Russia and Sweden established the Barents Euro-Arctic transport zone (BEATA) cooperation forum in May 1998.

The Barents region's Joint transport plan identifies 14 major cross-border multimodal transport routes that are crucial for its positioning. From the point of view of their development, the transport network in the Barents region should become denser and provide a sufficient number of effective transport corridors to increase the competitiveness of trade and industry, as well as to ensure the attractiveness of the Barents region for living and business activities. A number of areas that affect the European Union countries, such as Finland and Sweden, are recommended to be included in the Trans-European transport network (TEN-T).

A special place in the recommendations adopted at the Third Pan-European transport conference was given to the development of links between Europe and Asia, which in the future have a steady growth trend. Priority routes of Euro-Asian relations were identified:

Northern sea route;

Trans-Siberian railway and its extension to East Asia;

Extension of the corresponding corridors from Moscow to Novorossiysk and Astrakhan;

Development of relations in the direction of the Caspian sea via the Volga-Don canal;

Creating transport links along the Black sea coast to the Middle East and Central Asia, as well as transcontinental lines to all parts of Asia and the Pacific Ocean.

3 international Euro-Asian transport conferences were held in Saint Petersburg (Russia) in 1998, 2000 and 2003 in order to develop the problem of forming Euro-Asian relations. 
The Fourth Conference, scheduled to be held in 2006, did not take place for reasons related to the fact that the main effort should be focused not on the development of new proposals, but on the concentration of efforts on the implementation of previously adopted decisions.

Further studies on Euro-Asian transport links were conducted under the auspices of the UNECE with the participation of UNESCAP representatives. At the first stage, 2002-2007, specific data were collected on projects for developing the transport infrastructure of states. At the second stage (2008 -2012), the existing database was refined to take into account its development, as well as the formation of close cooperation of national coordinators in order to use reliable, safe and effective land communications between Europe and Asia in addition to sea transport, which is currently the main intercontinental transport. In phase III (2013-2017), specific data on container transport collected in almost 40 countries in Europe and Asia were analyzed, which led to the conclusion that road and rail transport along the Euro-Asian corridors is a complement to, rather than a competitor to, sea transport, providing alternative delivery options, especially for expensive and urgent goods, including in the context of growing e-commerce between Europe and Asia.

The most important decisions on the development of Euro-Asian destinations by ITC were enshrined in the Declaration adopted at the Second Euro-Asian transport conference (2000). First of all, this is an intergovernmental Agreement on the creation of the NorthSouth corridor signed by Russia, Iran and India, and later joined by a number of other states [7].

In addition, priority areas for the development of Euro-Asian relations were identified:

The Northern sea route (NSR) is the shortest route between the European part of Russia and the Far East. The route from St. Petersburg to Vladivostok - $14000 \mathrm{~km}$. Route through the Suez canal over $23000 \mathrm{~km}$. Development of transportation along the NSR is not only with the organization of international transport of goods, but also the solution to the problems of the North "importation" in the regions adjacent to the coast of the Arctic ocean (Tyumen oblast, Krasnoyarsk region, Yakutia, Chukotka).

The "East-West" direction ("Transsib" corridor) includes the main component: BerlinWarsaw-Minsk-Moscow-Yekaterinburg - Vladivostok / Nakhodka and branches: St. Petersburg -Kirov; Kiev-Kharkiv - Samara-Kurgan; Novorossiysk-Volgograd - Samara; Rostov-on-don - Volgograd; Kurgan - Petropavlovsk - Kazakhstan; Ulan-Ude - Mongolia; Chita - Zabaikalsk - China. One of the main problems in the development of this area today is the inefficiency of customs technologies.

The "North-South" direction includes the main component: Finland-St. Petersburg Moscow-Astrakhan - the Caspian sea-Iran - the Persian Gulf countries / India and branches: St. Petersburg -Murmansk; St. Petersburg-Belarus-Ukraine (Kiev-black sea ports): Moscow-Kiev; Kaliningrad-Vilnius-Minsk-Kiev; Moscow-Rostov-on-Don-Novorossiysk; Astrakhan - Makhachkala - Azerbaijan; Rostov-on-don-Makhachkala.

Currently, the existing Euro-Asian transport links (EATL) are consolidated on 9 railway and 7 road routes. In fact, the formation and integration of the EATL is the process of creating and further developing separate international transport systems, which should be considered as separate objects of research when considering the problem in a comprehensive way.

The existing outline of the EATL railway routes largely coincides with the railway corridors developed by the Organization for Railway Cooperation (OSJD), established in 1956, which at that time mainly included railway transport of socialist countries with its headquarters in Sofia (Bulgaria). At the moment of the OSJD corridors - 13 ). In addition, another important document developed within the framework of OSJD in 1996 is the "Agreement on organizational and operational aspects of combined transport in Europe Asia", which was based on the European agreement - AGTC. 
It should also be noted that some studies on the development of international transport systems are conducted in Central Asia. In particular, this applies to the formation of the CAREC strategy (Central Asian regional economic cooperation) on transport and trade facilitation. Periodic Ministerial conferences address issues related to the integrated development of the region's transport network, including security, institutional changes, customs services, and other issues. Currently, ten countries in the region have identified 6 main transport corridors.

In 2004, after a significant expansion of the EU from 15 to 25 (and by 2013 to 28) countries, the policy of the European Union required a corresponding adjustment. In April 2004, it adopted a new comprehensive plan to establish a Trans-European transport network (TEN) on its territory by 2020. This new plan defines as investment priorities 9 main TransEuropean corridors and 5 multimodal transport axes, the main function of which is long distance and international transportation. It applies to the territory of the expanded EU, as well as candidate countries for EU membership. The growth of the EU means that its external borders have moved to the East and South, and the EU has several new neighboring countries (figure 1).



Fig. 1. Trans-European network (TEN-T) of EU countries (2013).

\section{Conclusions}

After the expansion, significant components of the pan-European corridors and 2 panEuropean transport zones formed at Pan-European transport conferences were included in the EU transport system, i.e. they became an integral part of the Trans-European transport network, which necessitates the revision and, in some cases, redevelopment of these corridors. In essence, we are talking about a certain transformation of international transport systems, the development of one of them by absorbing a significant part of 
another system, in this case, the previously formed structure of pan-European transport corridors.

The total length of 10 pan-European transport corridors at the time of their completion was 27.3 thousand $\mathrm{km}$. After the EU expansion and the formation of the EEU, $76 \%$ of the length of the corridors were included in the Trans-European transport network (TEN), $14.9 \%$ were included in the new international transport system - the system of the Eurasian economic Union (the Treaty on the creation of the EEU, which united Russia, Belarus, Kazakhstan, Kyrgyzstan, and Armenia, entered into force in January 2015), which is currently at the stage of development, and 9.1\% remained in Ukraine and Moldova.

During the Soviet Union's existence, the so-called Unified transport system (UTS) was formed and operated reliably on its territory, its distinctive feature was to ensure the coordinated development and operation of all types of transport, taking into account the maximum satisfaction of transport needs at minimum costs [8]. After the USSR ceased to operate as a single state entity, 15 separate countries with their own transport system appeared. In the course of subsequent evolution, these separate transport systems became part of various international transport systems. The transport of the Baltic States after their accession to the EU was integrated into the Trans-European network (TEN-T), the transport systems of the other states are now more integrated into the international transport systems of the Eurasian transport routes, the OSJD system and the regional level systems [3]. The remaining parts of the pan-European transport corridors after EU enlargement can also be included in these systems.

Thus, the processes associated with the formation and development of international transport systems at the present stage require their own understanding and additional research, including determining the feasibility and sustainability of their operation. Necessary theoretical and conceptual trends in the international transport systems, the study of normative-legal support of their operation, the modeling of interaction between different modes of transport, their development prospects, it is possible to assess the effectiveness and other attributable to the issue of questions.

\section{References}

1. V.I. Arsenov, Bulletin of transport information, 6, 6-11 (1996)

2. V.V. Baginova, Applicant-Appendix to the World of transport magazine, 2, (10) 14-17 (2015)

3. Baginova V. V. International transport corridors: regional projections// World of transport, 2-1(5), 76-84 (2004)

4. A.A. Zenkin, Transport: science, technology, management, 7, 11-20 (2017)

5. A.A. Zenkin, Bulletin of transport information, 2, 16-20 (1998)

6. A.A. Zenkin, Transport: science, technology, management, 5, $42-47$ (2017)

7. A.A. Zenkin, Applicant-Appendix to the World of transport magazine, 1, 19-21 (2015)

8. G.N. Kovshov, Bulletin of transport information, 10, 30-32 (1998)

9. L.B. Vardomsky, M.O. Turaeva, Development of the post-soviet transport corridors in terms of contemporary geopolitical and economic challenges (Institute of Economy, Russian Academy of Sciences, Moscow, 2018)

10. V.I. Korolevskaya, Bulletin of transport information, 10, 20-28 (2018) 